\title{
Awareness About Sexually Transmitted and Other Infections of the Reproductive Tract, Risk Factors and Other Predictors in Women
}

\author{
Azizeh Farshbaf Khalili ${ }^{1}$; Mahnaz Shahnazi ${ }^{2}$; Sedighe Rezaie ${ }^{3}$; Hanieh Salehi Pourmehr ${ }^{4, *}$ \\ ${ }_{1}$ NPMC Research Center, Faculty of Nursing and Midwifery, Tabriz University of Medical Sciences, Tabriz, IR Iran \\ ${ }_{2}^{2}$ Faculty of Nursing and Midwifery, Tabriz University of Medical Sciences, Tabriz, IR Iran \\ ${ }^{3}$ Faculty of Nursing and Midwifery, Gillan University of Medical Sciences, Rasht, IR Iran \\ ${ }^{4}$ Neuroscience Research Center, Faculty of Nursing and Midwifery, Tabriz University of Medical Sciences, Tabriz, IR Iran \\ ${ }^{*}$ Corresponding author: Hanieh Salehi Pourmehr, Neuroscience Research Center, Faculty of Nursing and Midwifery, Tabriz University of Medical Sciences, Tabriz, IR Iran. Tel: + 98- \\ 4114796770, Fax:+ 98-4114796969, E-mail: poormehrh@yahoo.com
}

Received: September 7, 2014; Revised: October 1, 2014; Accepted: October 9, 2014

\begin{abstract}
Background: Genital tract infection is one of the major causes of morbidity and complications in both women and men.
Objectives: This studyaimed to determine the level of awareness about risk factors and other predictors of sexually transmitted and other infections of the genital tract.

Patients and Methods: This analytic cross-sectional study was carried on 584 women aged 15-49, who had referred to health care centers of Tabriz, Iran during 2013. Multi-stage cluster sampling was performed and the data-collecting tool was a questionnaire, for which validity and reliability were determined. Descriptive and inferential statistics (independent t-test, one-wayANOVA, and univariateand multivariate analysis) were used to analyze the data using the SPSS 17 software.

Results: The mean \pm SD score of awareness about non-sexual infections was $9.69 \pm 3.2$ with a range of 0 to 15 . The mean \pm SD score of awareness on sexually transmitted infections was $17.08 \pm 7.42$ with a range of 0 to 37. Multivariate analysis adjusting for potential confounding factors showed a statistically significant relationship between awareness score of non-sexual infections and variables of "sex only with husband", "anal, oral, anal-oral sex" and "marriage more than once". There was also a significant relationship between awareness of sexually transmitted infections with "anal, oral, anal-oral sex","marriage more than once" and "history of blood transfusion in husband". Thus, the awareness score of the following women was higher than others $(\mathrm{P}<0.05)$, those whose sex was not limited to their husband, had sex in unusual ways, reported a history of husband's blood transfusion, married only once.

Conclusions: The results of this study revealed that knowledge and understanding of subjects about sexual diseases is undesirable. So to increase awareness, women and girls must be sensitized to the importance of this issue.
\end{abstract}

Keywords:Reproductive Tract Infections; Risk Factors; Awareness; Women; Iran

\section{Background}

Sexually transmitted diseases (STDs) are a major health problem affecting mostly young people not only in developing, but also in developed countries (1) and all sexually active people are exposed to the risks of these diseases (2). Sexually transmitted diseases include diseases that are transmitted from one person to another during sexual (genital-anal-oral or pharyngeal) contact. There are more than 30 pathogens known to be transmitted sexually (3-5), which may be contaminated by viruses (genital herpes, human papilloma virus (HPV) or genital warts, hepatitis B and HIV), bacteria (gonorrhea, chancroid, syphilis and chlamydia) or parasites (pubic lice) (6). Some are associated with pain, ulcers and discharge, but most remain without any signs for a long time, and may be transmitted to others through unprotected sex and cause pelvic inflammatory disease (PID) and infertility, and consequently lead to ectopic pregnancy (6-8). Some of these diseases (gonorrhea, syphilis, chlamydia and trichomoniasis) can be cured, however their incidence has increased by about 11\% between 2008 and 2005; others STDs (hepatitis B, HIV, herpes simplex virus (HSV) and $\mathrm{HPV}$ ) are not curable (2, 9-12). These diseases are a major cause of illness, infertility, long-term morbidity and mortality associated with serious physical and psychological effects in women, men and their infants (13). Some sexually transmitted infections (STIs) can increase the risk of HIV by three or more times (14). Certain STIs, such as syphilis, gonorrhea, HIV infection, hepatitis B and chancroid, are most concentrated within "core populations" characterized by high rates of partner change, multiple concurrent partners, or high connection to "dense", sexual networks (15). The age group of 15 to 49 years has the greatest prevalence of sexually transmitted diseases, where nearly half of the infections occur in young adults and adolescents aged 14-24 years $(1,16)$. These data suggest the need for emergency prevention (15). The declining age at first sexual intercourse has been proved to be a possible explanation for the increase in the number of STDs $(17,18)$ and

Copyright ( 2014 , Infectious Diseases and Tropical Medicine Research Center; Published by Kowsar. This is an open-access article distributed under the terms of the Creative Commons Attribution-NonCommercial 4.0 International License (http://creativecommons.org/licenses/by-nc/4.0/) which permits copy and redistribute the material just in noncommercial usages, provided the original work is properly cited. 
the reluctance of adolescents to use condoms is another possible explanation (19-21). According to the statistics collected from medical universities and health services of Iran, until 2013, a total of 26125 individuals infected with HIV/AIDS have been identified. Among those registered, $89.8 \%$ were male and $10.2 \%$ were female and about half of the patients were aged between 25 and 34 years. The causes of HIV infection among cases that have been registered from 1986 to the present date are respectively, shared needles by injecting drug users (69.6\%), sexual contact (12\%), receiving blood and blood products (1\%), and transmission from mother to child (1\%). Although the number of people with AIDS is low in Iran, based on the current data, the World Health Organization (WHO) has reported that AIDS is seriously increasing in this country especially in women. More than $90 \%$ of women with HIV are infected through their husbands without being aware (22). In 2013, 33\% of HIV transmissions were thorough sexual contact. However, in 2002, only $10 \%$ of HIV cases had become infected through sex. Talking about AIDS in Iran is accompanied by moral and secular restrictions. Also talking about puberty, sexual health and sexually transmitted diseases in families is still limited. Expression of disease may result in moral stigma from family, friends and the community. Therefore, these diseases spread secretly and hard to control (23). By considering religious and ethical issues, teachings and warnings should be provided at the basic level. Education and consultation about STIs should be a priority for health policy makers and should include all groups of adolescents, women, men, and health sector employees (24). The role of health workers, including midwives in training is very important. According to the Ministry of Health guidelines, training, tips and counseling on a variety of health issues, including sexual and sexually transmitted diseases is one of the important tasks of midwives (25). Recognizing the community's educational needs can be helpful for improving public health (26).

\section{Objectives}

With regards to the increase of STIs in Iran, this study was performed with the aim of determining risk factors and other predictors of awareness on sexually transmitted and other infections of the genital tract in women who had referred to health centers of Tabriz.

\section{Patients and Methods}

This analytic cross-sectional research, investigated risk factors and other predictors of awareness about sexually transmitted and other infections of genital tract in women who had referred to health centers of Tabriz, Iran, during the year 2013. The population consisted of all women who had referred to health centers of Tabriz. Inclusion criteria were: referral to Tabriz health centers and having records, having more than elementary school literacy, willingness to participate in the research, not being single, age range of 15 to 49 . The exclusion criteria were: individuals' refusal to participate in the study and not filling more than $20 \%$ of the questionnaire. The sample size was primarily estimated as 384 individuals by using the formula for calculating proportion; considering that $\mathrm{P}=50 \%, \mathrm{z}=1.96$, and $\mathrm{d}=0.05$ and that the design effect equaled 1.5 , the sample size was calculated as 584. At first, a list of all the health care centers and subcenters of Tabriz (totally 65 centers and sub-centers) was obtained from the Health Center of Tabriz. Then, sampling was done in two stages by the multistage cluster sampling method. Randomly 22 centers and sub-centers (nine centers and 13 sub-centers) were selected among 27 centers and 38 health sub-centers. During the next stage, regarding the sample size, 25-30 health records were randomly selected from all the records of women and after phoning these women and explaining the study, they were invited for an interview on a specific day. Sampling during both stages was done randomly through the following website www.randomizer.org. Firstly, 621 eligible women were selected, of whom 37 declined to participate and 584 consented. The data collecting tool of this study was a researcher-regulated questionnaire which was designed according to information in books and articles. This questionnaire consisted of two parts: the first part was related to questions about awareness on STIs and non-sexual genital infections and risk factors while the second part was related to the socio-demographic characteristics and patient's history of midwifery and reproduction. The validity of the tool was determined using comments provided by ten academic members of Tabriz University of Medical Sciences through content validity. Content validity reliability (CVR) and content validity index (CVI) indices were 0.72 and 0.81 , respectively. The reliability was determined through the test and re-test method on 30 subjects. It was assessed by the Cronbach's alpha coefficient which was $r=0.81$. After approval of the proposal and scientific confirmation of the questionnaire, permission was obtained from the ethical committee of research of Tabriz University of Medical Sciences. The questionnaire was completed by subjects, after the researcher introduced the study objectives and explained the differences between natural secretions of the genital system and infections. In order to identify the level of awareness, score 1 was given to "right" answers and zero was given to "wrong" or "I don't know" answers and the total score for each individual was calculated. The total score for each individual, according to the number of awareness questions about non-sexual genital infections was between 0-15. Knowledge score of $<5$ was considered as weak, 6-10 as average and 11-15 as good. Also, the total score for each individual according to the number of awareness questions on STIs was between 0-37. Knowledge score of $<12$ was considered as weak, 13-24 as average and 25-37 as good. It should be noted that from 37 questions, 14 questions were related to awareness regarding HPV. Before data collection, ethical satisfaction form 
was given to the study subjects and written consent was obtained and voluntariness and confidentiality of the information were emphasized. The participants could express that they had no satisfaction and willingness. It was emphasized that the questionnaire should be answered carefully in order to arrange educational programs and promote health-related knowledge of all the members of the society. This study was approved by the research deputy of Tabriz University of Medical Sciences (code: 91101).

\subsection{Statistical Analysis and Statistical Software}

After collecting the questionnaires, the data were analyzed by using the SPSS software (ver.17). Descriptive statistics were used to examine the frequency distribution, mean and 95\% confidence interval (CI) of the mean. In order to answer the questions of the research, independent t-test, Mann-Whitney, Kruskal-Wallis and one-way ANOVA were used and in order to control the confounding factors and identify their effect, univariate and multivariate statistics were used. Before conducting the multivariate analysis, assumptions of the regression were studied, including the normality of the residuals, the homogeneity of the residual variance, the multicollinearity of independent variables, and the independence of the residuals. The variables with $\mathrm{P}<0.1$ were entered in the model. In this study, $\mathrm{P}<0.05$ was considered significant.

\section{Results}

Most of the participants (48.3\%) and their husbands (33\%) had high school diplomas. Most of the individuals (56.1\%) were aged 20 to 29 years (90.2\%), were housewives and had sufficient income (59.4\%). The mean \pm SD score of awareness about non-sexual infections was $9.69 \pm 3.2$ with a range of 0 to15, and therefore there was an average level of awareness in this regard. The mean \pm SD score of awareness on sexually transmitted infections was $17.08 \pm 7.42$ with a range of 0 to 37 and thus there was poor to moderate level of awareness in this regard. The median (min, max) of the individuals' scores regarding knowledge about HPV was three $(0,13)$ and thus was very low (Table 1). There was a significant relationship between the score of individual awareness on sexual and non-sexual infections and age, education and occupation $(\mathrm{P}<0.05)$. Individuals aged less than twenty years, had the least score of awareness. The score of awareness was higher in participants with higher level of education (both herself and her husband) and in those working outside their home (Table 2). In relation to risk factors, almost half of the participants had a history of genital tract infections. There was a statistically significant relationship between "sex only with husband", "oral, anal, and vaginal-oral sex", and "history of marriage more than once" and the score of awareness on sexual and non-sexual infections (Table 3). Regarding questions about non-sexual infections, the lowest number of correct answers was given to the following phrases, "long-term use of antibiotics, may predispose patients to genital tract infections" (18.9\%) and "pregnant women or women with diabetes are more susceptible to genital infections" (35.2\%). Also, the least accurate answers for questions on sexually transmitted infections, belonged to "HPV is not treated with antibiotics" (6.4\%) and "there is a vaccine to prevent HPV" (8.4\%), respectively. The most correct answers for questions about non-sexual infections belonged to the following phrases, "rapid diagnosis and treatment of some genital tract infections can prevent their risks" (90.1\%), With regard to sexually transmitted infections, the most accurate answers were given for the following phrases, "itching or burning of genitalia is one of the symptoms of STIs" (92.6\%) and " burning or pain when urinating is one of the symptoms of STIs" (86.9\%). Multivariate analysis adjusting for potential confounders showed a significant statistical relationship between awareness score and age. So that, the highest scores for questions on non-sexual infections and STIs belonged to $40-49(\beta=4.58,95 \% \mathrm{CI}=1.21-7.95)$ and $20-29(\beta=2.05$, $95 \% \mathrm{CI}=0.325-3.781)$ years-old participants, respectively. Also, there was a significant statistical relationship between awareness score and educational level. Awareness score in people with elementary education was significantly less than people with university degrees regarding non-sexual infections $(\beta=-1.56,95 \% \mathrm{CI}=-2.82$ to -0.29$)$ and STIs ( $\beta=-4.67,95 \% \mathrm{CI}=-7.61$ to -1.73$)$. Besides, there was a similar statistical relationship between awareness score and husband's educational level. Multivariate analysis indicated a statistically significant relationship between awareness score of non-sexual infections and variables of "sex only with husband" ( $\beta=$ 2.08, 95\% CI = 0.58-3.57), "anal, oral, and anal-oral sex" ( $\beta$ $=-2.10,95 \% \mathrm{CI}=-3.65$ to -0.56$)$ and "marriage more than once" ( $\beta=2.195,95 \% \mathrm{CI}=0.909-3.481)$. There was also a significant relationship between awareness of STIs and "anal, oral, anal-oral sex" ( $\beta=-3.83,95 \% \mathrm{CI}=-7.445$ to -0.226), "marriage more than once" ( $\beta=4.493,95 \% \mathrm{CI}=$ 1.490-7.497), and "history of blood transfusion in husband" ( $\beta=-1.78,95 \%$ CI $=-5.95-2.39)$. So that, awareness scores of the following women was higher than the rest, those whose sex was not limited to their husband, had sex in unusual ways, those who reported a history of husband's blood transfusion, and those that had married only once (Table 4).

Table 1. Awareness on Sexual and Non-Sexual Transmitted Infections $^{\text {a }}$

\begin{tabular}{lcc}
\hline $\begin{array}{l}\text { Awareness } \\
\text { Level }\end{array}$ & $\begin{array}{c}\text { Non-Sexual } \\
\text { Infections }\end{array}$ & $\begin{array}{c}\text { Sexually Transmitted } \\
\text { Infections }\end{array}$ \\
\hline Weak & $61(10.8)$ & $162(28.2)$ \\
Average & $254(45.1)$ & $313(54.4)$ \\
Good & $248(44)$ & $100(17.4)$ \\
\hline
\end{tabular}

${ }^{\mathrm{a}}$ Data are presented as No.(\%). 
Farshbaf Khalili A et al.

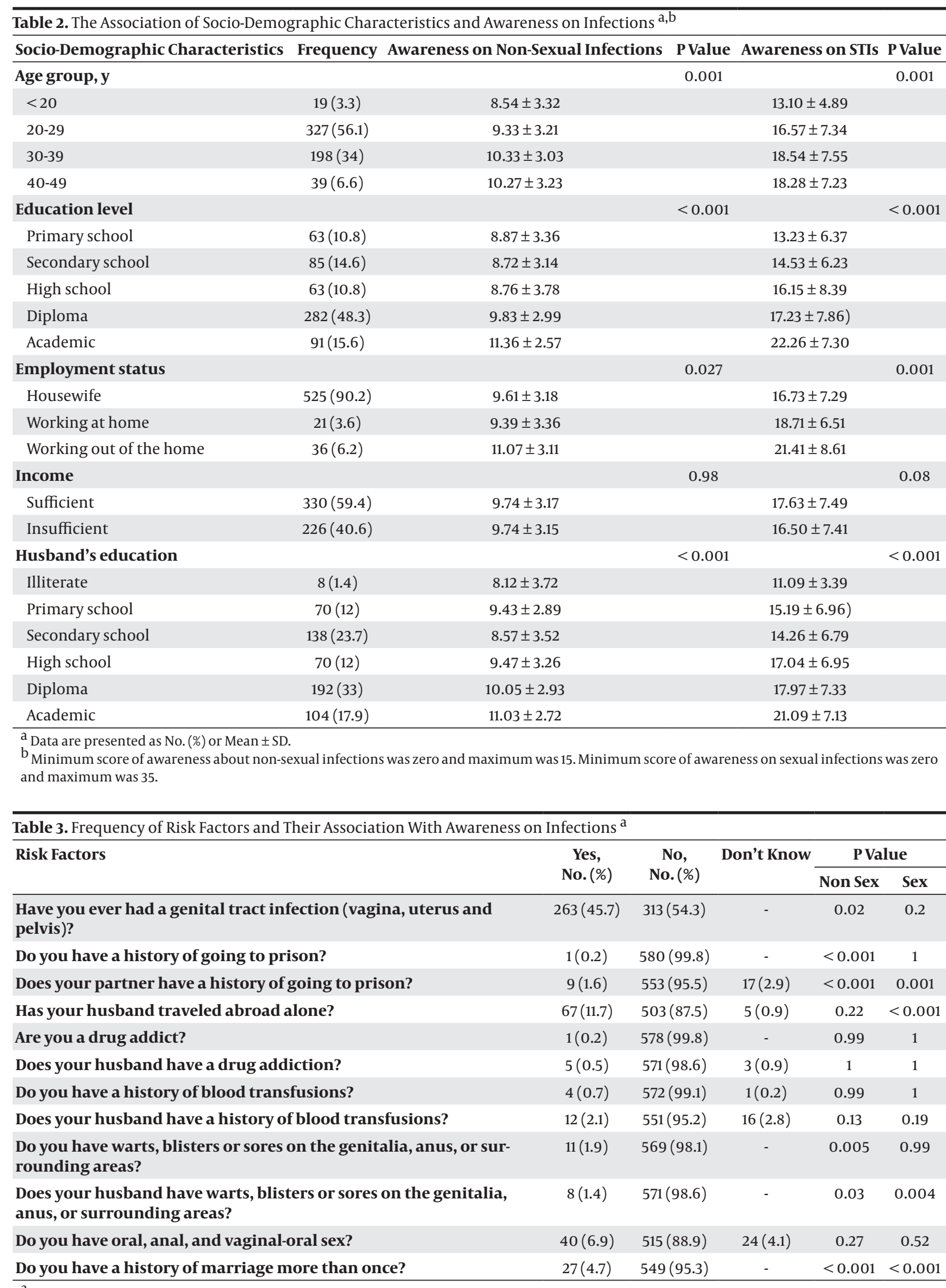

$\mathrm{a}_{\text {Independent } \mathrm{t}-\text { Test, one-way ANOVA. }}$ 
Farshbaf Khalili A et al.

Table 4. Predictive Value of Potential Confounding Variables for Awareness Determined Using the General Linear Model ${ }^{\text {a }}$

\begin{tabular}{|c|c|c|c|c|}
\hline \multirow[t]{2}{*}{ Variable } & \multicolumn{2}{|c|}{ Awareness on Sexually Transmitted Infections } & \multicolumn{2}{|c|}{ Awareness on Non-Sexual Genital Infections } \\
\hline & $\beta($ CI 95\%) & P Value & $\beta($ CI 95\%) & PValue \\
\hline \multicolumn{5}{|l|}{ Education } \\
\hline Academic & Ref & & Ref & \\
\hline Primary school & $-4.674(-7.614-1.733)$ & $0.002^{\mathrm{a}}$ & $-1.556(-2.815-0.297)$ & $0.016^{\mathrm{a}}$ \\
\hline Secondary school & $-4.693(-7.302-2.085)$ & $<0.001^{\mathrm{a}}$ & $-1.541(-2.658-0.423)$ & $0.007^{\mathrm{a}}$ \\
\hline High school & $-1.144(-3.886-1.598)$ & 0.413 & $-0.591(-1.765-0.584)$ & 0.323 \\
\hline Diploma & $-2.942(-4.957-0.927)$ & $0.004^{\mathrm{a}}$ & $-0.869(-1.732-0.006)$ & $0.049^{\mathrm{a}}$ \\
\hline \multicolumn{5}{|l|}{ Age, $y$} \\
\hline $20>$ & Ref & & Ref & \\
\hline $20-29$ & $3.163(-0.872-7.197)$ & 0.124 & $2.053(0.325-3.781)$ & $0.02^{\mathrm{a}}$ \\
\hline $30-39$ & $3.338(0.070-6.605)$ & $0.045^{\mathrm{a}}$ & $0.702(-0.698-2.101)$ & 0.325 \\
\hline $40-49$ & $4.579(1.205-7.953)$ & $0.008^{a}$ & $1.478(0.034-2.923)$ & $0.045^{a}$ \\
\hline
\end{tabular}

\section{Wife education}

$\begin{array}{lccc}\text { Academic } & \text { Ref } & & \text { Ref } \\ \text { Illiterate } & -6.149(-12.100-0.199) & 0.043^{\mathrm{a}} & -2.716(-5.265-0.167) \\ \text { Primary school } & -3.047(-5.666-0.429) & 0.023^{\mathrm{a}} & -0.724(-2.658-0.423) \\ \text { Secondary school } & -3.728(-5.933-1.522) & 0.001^{\mathrm{a}} & -1.128(-2.073-0.183) \\ \text { High school } & -2.542(-4.977-0.107) & 0.041^{\mathrm{a}} & -0.886(-1.929-0.157) \\ \text { Diploma } & -1.209(-3.106-0.687) & 0.211 & -0.222(-1.034-0.590)\end{array}$

Anal, oral, Anal-oral sex

\begin{tabular}{|c|c|c|c|c|}
\hline Yes & Ref & & Ref & \\
\hline No & $-3.835(-7.445-0.226)$ & $0.037^{\mathrm{a}}$ & $-2.103(-3.649-0.557)$ & $0.008^{a}$ \\
\hline Don't know & $0.520(-1.802-2.842)$ & 0.66 & $0.480(-0.515-1.474)$ & 0.343 \\
\hline \multicolumn{5}{|c|}{ Sex only with husband } \\
\hline Yes & Ref & & Ref & \\
\hline No & $0.927(-2.559-4.412)$ & 0.602 & $2.077(0.585-3.570)$ & $0.006^{\mathrm{a}}$ \\
\hline \multicolumn{5}{|c|}{ Husband blood transfusion } \\
\hline Yes & Ref & & Ref & \\
\hline No & $-4.841(-10.652-0.97)$ & 0.102 & $-0.754(-3.243-1.735)$ & 0.552 \\
\hline Don’t know & $-1.780(-5.950-2.389)$ & $0.0402^{a}$ & $-0.824(-2.610-0.961)$ & 0.365 \\
\hline \multicolumn{5}{|c|}{ Genital infection } \\
\hline Yes & Ref & & Ref & \\
\hline No & $-0.913(-2.127-0.302)$ & 0.140 & $-0.596(-1.116-0.076)$ & $0.025^{\mathrm{a}}$ \\
\hline \multicolumn{5}{|c|}{ Marriage more than once } \\
\hline Yes & Ref & & Ref & \\
\hline No & $4.493(1.490-7.497)$ & $0.003^{\mathrm{a}}$ & $2.195(0.909-3.481)$ & $0.001^{\mathrm{a}}$ \\
\hline
\end{tabular}

$\mathrm{a}$ R Squared (non-sexual genital infections) $=0.206$ (Adjusted R Squared $=0.157$ ); R Squared (Sexually Transmitted Infections) $=0.240$ (Adjusted R Squared $=0.193$ ).

\section{Discussion}

In this study, awareness about genital infections was moderate. In a review study on genital tract infections studying the time frame between 1990 and 2010, among adolescents in European countries, awareness about the genital tract infections was reported average and below average with the exception of HIV/AIDS that was over $90 \%$ (1), which is consistent with the results of the present study. The mean \pm SD score of awareness about STIs was $17.08 \pm 7.42$ with a range of 0 to 37 , so subjects had poor to moderate level of awareness. In the study done 
by Mohammadi et al. mean scores were moderate on the nine-point STI/HIV/AIDS scale (3.86; SD = 2.13) and the three-point condom awareness index $(1.50 ; \mathrm{SD}=1.20)(27)$. Kolahi et al. in their study on a female at-risk population showed that most subjects knew that AIDS currently has no cure (81.2\%) and no vaccine (73.4\%). Most also knew that HIV is transmissible from people who do not know they are HIV positive (59.4\%), and that proper condom use (78.1\%) and having a single sexual partner (68.8\%) can reduce the possibility of infection. Of the participants, 43.4\% knew that an HIV-positive person can seem perfectly healthy (28). Shiferaw and colleagues in their study in Ethiopia showed that students' knowledge about some aspects of STD was low and only half of them knew that HIV is untreatable, and HIV can be transmitted through sex. Also knowledge about STIs was low (29). In another study in Pakistan, 25\% of people were aware about the ways of transmission and prevention of HIV (30). Zhang et al. in a study on Chinese university students showed that students had limited knowledge and awareness about common STIs, symptoms and complications. Most students had misconceptions about transmission and prevention of STIs. The internet was the main information resource for $76 \%$ of students (31). It should be noted that in our study, 14 out of 37 questions were related to awareness on HPV and the mean score was very low. There is much concern regarding low awareness and poor control of sexually transmitted diseases. We don't know the exact transmission modes of these diseases in the community. This indicates the poor performance of the healthcare system regarding sex-related complications. Moreover, because of embarrassment and shame in our society, general information about sexual diseases and rate of genital infections, especially amongst youth, as a high-risk group, is low in Iran. Obtaining accurate data directly is difficult and researchers can only rely on indirect information (32). However, introducing community-based education and giving the required information while considering moral and religious beliefs is necessary. Training programs should provide information about complications of genital infections in people including infertility, ectopic pregnancy, pelvic inflammatory disease, cervical cancer and adverse pregnancy outcomes such as spontaneous abortion, fetal death creation, delivery and postpartum infections. Such information may stop many people from having risky behaviors. In the present study, the score of awareness increased with enhancement of education. In addition, awareness score among employed women was more than housewives. Promotion of individual's educational level may increase their motivation and willingness to use a variety of educational resources, participate in educational programs and make use of past experiences. The positive and multiplier effects of education and general literacy on population health, particularly women's health, are well known and researched. Health literacy as a discrete form of literacy is becoming increasingly important for social, economic and health development (33). In a study on Indian railway employees and their family members by Chauhan et al. there was a significant correlation between level of education and knowledge (34). Also in another study by Das and colleagues in India, this relationship was confirmed (35). These studies are consistent with the results of the present study. Health education and prevention remain to be the main health care priorities in AIDS prevention (36). The results of this study showed that the awareness score of women in whom sex was not limited to their husband, had sex in unusual ways, reported a history of husband's blood, were higher than others. These results revealed that having risk factors of disease could lead to increasing awareness. Therefore, in order to raise awareness and improve behavior, women and girls must be sensitized to the importance of this issue. In this study, subjects were selected randomly from different regions and different social-economical levels. One of the limitations of this study was that the sample only included women who had referred to Tabriz health care centers, and therefore the results may not be generalized for all women. Also, due to the nature of the questions, there was a possibility of incorrect answers, which was partly controlled by emphasizing confidentiality and questionnaires not requiring the names of the participants. In this study, the data-collecting questionnaire was self-administered and so illiterate women were not studied. It is suggested that other similar studies on other groups of the society especially younger people, adolescents and school students should be performed, investigating their awareness level about genital infections in order to design necessary programs and achieve the goal of first level prevention for avoidance of risky behaviors. Genital tract infections are one of the major causes of morbidity and complications in both women and men. Therefore, primary prevention of these infections should be a health priority. Training courses about genital infections must be conducted for school-age adolescents and before marriage. Health educators must be complied with this strategy. This requires the promotion of awareness and knowledge to control the spread of sexually transmitted infections (including HIV/AIDS) among young people. Therefore, the need for more research on the awareness and education of the public about reproductive tract infections is necessary. Despite the importance of disease prevalence in the community, knowledge and understanding of women about sexual diseases and prevention methods is weak. Sexually transmitted disease clinics established to meet the needs of screening, treatment; health education and STD-related concepts are helpful. Furthermore, education programs must include the public and also health care providers.

\section{Acknowledgements}

We hereby thank the Deputy of Research of Tabriz University and School of Nursing and Midwifery, officials and professors of the School of Nursing and Midwifery, offi- 
cials of the Health Department of Tabriz and authorities and staff of the Health Centers and all the women who patiently assisted us in collecting the data.

\section{Authors' Contributions}

Study concept and design: Azizeh Farshbaf Khalili, Sedighe Rezaie. Analysis and interpretation of data: Azizeh Farshbaf Khalili,Mahnaz Shahnazi and Hanieh Salehi Pourmehr, Sedighe Rezaie. Drafting of the manuscript: Hanieh Salehi Pourmehr and Azizeh Farshbaf Khalili. Critical revision of the manuscript for important intellectual content: Azizeh Farshbaf Khalili, Mahnaz Shahnazi and Hanieh Salehi Pourmehr. Statistical analysis: Azizeh Farshbaf Khalili and Hanieh Salehi Pourmehr.

\section{Financial Disclosure}

This study was financially supported in part by Tabriz University of Medical Sciences.

\section{References}

1. Samkange-Zeeb FN, Spallek L, Zeeb H. Awareness and knowledge of sexually transmitted diseases (STDs) among school-going adolescents in Europe: a systematic review of published literature. BMC Public Health. 2011;11:727.

2. Bosch FX, Burchell AN, Schiffman M, Giuliano AR, de Sanjose S, Bruni L, et al. Epidemiology and natural history of human papillomavirus infections and type-specific implications in cervical neoplasia. Vaccine. 2008;26 Suppl 10:K1-16.

3. Satterwhite CL, Torrone E, Meites E, Dunne EF, Mahajan R, Ocfemia MC, et al. Sexually transmitted infections among US women and men: prevalence and incidence estimates, 2008. Sex Transm Dis. 2013;40(3):187-93.

4. Owusu-Edusei K, Jr., Chesson HW, Gift TL, Tao G, Mahajan R, Ocfemia MC, et al. The estimated direct medical cost of selected sexually transmitted infections in the United States, 2008. Sex Transm Dis. 2013;40(3):197-201.

5. United States Centers for Disease Control and Prevention.. Incidence, Prevalence, and Cost of SexuallyTransmitted Infections in the United States.: CDC; 2013.

6. Andersson-Ellstrom A, Milsom I. Knowledge about the prevention of sexually transmitted diseases: a longitudinal study of young women from 16-23 years of age. Sex Transm Infect. 2002;78(5):339-41.

7. Catchpole M. Sexually transmitted infections: control strategies. BMJ. 2001;322(7295):1135-6.

8. Simms I, Stephenson JM. Pelvic inflammatory disease epidemiology: what do we know and what do we need to know? Sex Transm Infect. 2000;76(2):80-7.

9. Dunne EF, Nielson CM, Stone KM, Markowitz LE, Giuliano AR. Prevalence of HPV infection among men: A systematic review of the literature. J Infect Dis. 2006;194(8):1044-57.

10. Dunne EF, Klein NP, Naleway AL, Baxter R, Weinmann S, Riedlinger K, et al. Prevalence of HPV types in cervical specimens from an integrated healthcare delivery system: baseline assessment to measure HPV vaccine impact. Cancer Causes Control. 2013;24(2):403-7.

11. Looker KJ, Garnett GP, Schmid GP. An estimate of the global prevalence and incidence of herpes simplex virus type 2 infection. Bull World Health Organ. 2008;86(10):805-12.

12. World Health Organization.. Global incidence and prevalence of selected curable sexually transmitted infections. Geneva: WHO; 2008. Available from: http://www.who.int/reproductivehealth/publications/rtis/stisestimates/en/index.html.

13. Andrews G. Womans sexual health.London: Bailliere Tindal; 2005.

14. Centers for Disease Control and Prevention.. Sexually Transmitted Diseases (STDs). 2014. Available from: http://www.cdc.gov/STD/.
15. World Health Organization.. Education material for teachers of midwifery/ Foundation module/ the midwife in community.second edition.France: WHO; 2008.

16. Ohene S, Akoto I. Factors associated with sexually transmitted infections among young ghanaian women. Ghana Med J. 2008;42(3):96-100.

17. Panchaud C, Singh S, Feivelson D, Darroch JE. Sexually transmitted diseases among adolescents in developed countries. Fam Plann Perspect. 2000;32(1):24-32.

18. World health Organization.. Prevalence and incidence of selected sexually transmitted infections, Chlamydia trachomatis, Neisseria gonorrhoeae, Syphilis and Trichomonasvaginalis.Geneva: WHO; 2011.

19. Ford N. The AIDS awareness and sexual behaviour of young people in the South-west of England. J Adolesc.1992;15(4):393-413.

20. United Nations \& AIDS.. Global report on the global AIDS epidemic 2013.: UNAIDS;. Available from: http://www.unaids.org/en/media/ unaids/contentassets/documents/epidemiology/2013/gr2013/ UNAIDS_Global_Report_2013_en.pdf.ISB.

21. Rijsdijk LE, Bos AE, Lie R, Ruiter RA, Leerlooijer JN, Kok G. Correlates of delayed sexual intercourse and condom use among adolescents in Uganda: a cross-sectional study. BMC Public Health. 2012;12:817.

22. Ministry of Health and Medical Education.. Recent statistics on infection of HIV/AIDS in the Islamic Republic of Iran to exploit public 2013. 2013. Available from: http://aids.behdasht.gov.ir/.

23. Wikipedia.. HIV/AIDS in Iran.: Wikipedia;. Available from: http:|| en.wikipedia.org/wiki/Category:HIV/AIDS_in_Iran.

24. Ministry of Health and Medical Education . Brief about AIDS. Department the Health Center of Communicable Disease Management.. Available from: http://aids.behdasht.gov.ir/index. aspx?siteid=328\&pageid=50495.

25. Ministry of Health and Medical Education.. Duties of Midwives. Available from: http://www.rums.ac.ir/uploads/rums_mamaei_ aeiname_ts.pdf.

26. Tang KC, Nutbeam D, Aldinger C, St Leger L, Bundy D, Hoffmann AM, et al. Schools for health, education and development: a call for action. Health Promot Int. 2009;24(1):68-77.

27. Mohammadi MR, Mohammad K, Farahani FK, Alikhani S, Zare M, Tehrani FR, et al. Reproductive knowledge, attitudes and behavior among adolescent males in Tehran, Iran. Int Fam Plan Perspect. 2006;32(1):35-44.

28. Kolahi AA, Rastegarpour A, Abadi AR, Nabavi M, Sayyarifard A Sohrabi MR. The knowledge and attitudes of a female at-risk population towards the prevention of AIDS and sexually transmitted infections in Tehran.J Res Med Sci. 2011;16(11):1452-8.

29. Shiferaw Y, Alemu A, Girma A, Getahun A, Kassa A, Gashaw A, et al. Assessment of knowledge, attitude and risk behaviors towards HIV/AIDS and other sexual transmitted infection among preparatory students of Gondar town, north west Ethiopia. BMC Res Notes. 2011;4:505.

30. Khan MS, Unemo M, Zaman S, Lundborg CS. Knowledge, attitudes and practices regarding human immunodeficiency virus/ acquired immune deficiency syndrome and sexually transmitted infections among health care providers in Lahore, Pakistan. $J$ Ayub Med Coll Abbottabad. 2009;21(4):1-6.

31. Zhang D, Pan H, Cui B, Law F, Farrar J, Ba-Thein W. Sexual behaviors and awareness of sexually transmitted infections among Chinese university students. J Infect Dev Ctries. 2013;7(12):966-74.

32. Mohebbi MR. Female sex workers and fear of stigmatisation. Sex Transm Infect. 2005;81(2):180-1.

33. Kickbusch IS. Health literacy: addressing the health and education divide. Health Promot Int. 2001;16(3):289-97.

34. Chauhan H, Lal P, Kumar V, Malhotra R, Ingle GK. Awareness status about HIV/AIDS among Indian railway's employees and their family members. J Commun Dis. 2008;40(4):295-9.

35. Das A, Babu GR, Ghosh P, Mahapatra T, Malmgren R, Detels R. Epidemiologic correlates of willingness to be tested for HIV and prior testing among married men in India. Int J STD AIDS. 2013;24(12):957-68.

36. Ghabili K, Shoja MM, Kamran P. The Iranian female high school students' attitude towards people with HIV/AIDS: a cross-sectional study. AIDS Res Ther. 2008;5:15. 